\title{
Study on the Configuration Design of Engineering Graphics
}

\author{
Chaoyong Guo, Haiying Huang, Juan Li \\ Department of Vehicles and Electrical Engineering \\ Ordnance Engineering College \\ Shijiazhuang, China \\ Guochy1963@163.com
}

\begin{abstract}
The focus of the configuration design of engineering graphics is mainly about the expression of configuration and its projection. According to the teaching content and the different stage, configuration design demonstrates various forms. It is an effective form of training innovative thinking ability of students, and reduces non intelligence factors, improve the teaching effect.
\end{abstract}

Keywords- engineering graphics teaching; configuration design; innovation ability training.

\section{INTRODUCTION}

The basic goal of education is to cultivate students' engineering graphics illustration, reading, drawing ability and space imagination. Its highest goal is to cultivate students innovative design ability. The main task of training innovative talents is to cultivate students' creative thinking ability, as well as the creative way of thinking of engineering graphics. The practical process determines that is one of the effective ways to improve students' ability of creative thinking training [1]. In this paper the author focuses on engineering graphics recognition configuration design and the engineering graphics education in strengthening students' ability to explore the configuration creative design.

\section{The ConNotation of Configuration Design of ENGINEERING GRAPHICS}

Configuration design of engineering graphics is a training mode formed in the teaching practice of project drawings in recent years. Engineering drawing is the carrier of the image of innovative thinking ability and the pattern of expression. Although present there is no uniform definition, it generally refers to the process of designing different idea of graphic, shape, parts, assembly, and specific expression in engineering drawing is given according to the given conditions.

Configuration design is about the image of the creative process description. It expresses a kind of thinking process and results. The "structure" is a conception, namely composition, design, imagine and meaning, and it is a kind of thinking activity and thinking process. It is the mental activity of reaction. "Type" is the shape, form, and pattern, model and so on, and it is the result of thinking activity. "Design" refers to "according to certain requirements, to form the first formulation method, pattern etc.” The design can be collected in all of the work process, such as mechanical engineering design, and it contains the principle scheme, performance index, structure form, parameter calculation, experiment method, process approach, material selection, application environment and all other work, which also express a certain phase of the work by using the principle of design, process design. Design and expression of a creative process, as designers expected, its results are not necessarily the "shape", but also can be the product of a plan, a scheme and a method, etc. [2].

Configuration design is to limit the design on configuration. In this way, "configuration" and "design" has the same basic connotation. Configuration and configuration design are basically the same, and the design here is to strengthen and draw configuration, making people feel it more perfect and clearer. In this sense design focuses on configuration.

Configuration design of engineering graphics should be closely around the engineering drawing course, teaching the basic requirements of the provisions of the scope and goals of cultivation. The introduction of configuration design aims to improve the teaching effect and the proper drawing teaching content, but not go beyond the teaching mission. The course is mostly conducted in the grade of the opening. The students are lack of knowledge in mechanics, mechanical principles, mechanical process, engineering materials and other aspects of knowledge, and yet do not have the ability to carry out product design. Therefore, the configuration of activities must be around the space imagination and thinking, graphic solving, graphic expression and drawing skills.

Configuration design is a kind of ability of the designers. Configuration design is not equal to the product design, not the pursuit of activities through designing perfect and practical results. The introduction of configuration design in engineering graphics teaching is to better cultivate students' ability of thinking, intellectual development, and strengthen the image of innovation thinking ability training.

\section{THE CONTENTS AND THE FORMS OF CONFIGURATION DESIGN OF ENGINEERING GRAPHICS}

A variety of configuration design project in engineering graphics can be classified from different angles [3]. Starting from the purpose of configuration design, it can be divided into the following categories: (1) Strengthen the concept of configuration design. It will greatly enhance the understanding of the seven kinds of position line location characteristics and projection characteristics; (2) The configuration design skill training. It is good to use the drawing tool and drawing skills training and planar design integration. (3) The body configuration design. If given a certain size of the cuboids and 
asked to do the digging and cutting and stacking transform, the entity volume does not change isometric transform, expressed by the three view drawing and axonometric; or given a view to add another two views, the ever-changing results are quite abundant. (4) The expression of configuration design. If the expression of conception and design is with four or more views of the body, the conception and design requires the use of ladder like expression shape form etc.. Students can deepen the understanding and use expression method to improve the ability. (5) Function (principle) of configuration design. If asked to design a cup-shaped stereo, which can be a cup, a pen holder, and its function is clear to everyone, the results may vary greatly. (6) The structural configuration design. If given a shaft or a blank map, and require students to modify into a reasonable structure, or to realize the sealing connection, or according to the schematic to complete structure, it can deepen understanding and application of process structure or assembly structure. (7) Creative configuration design. Modification has the potential to become the product design. Also according to the curriculum content and teaching process, configuration design is classified as: design, point line surface configuration of planar graphic configuration design, intercepting and intersecting configuration design, combination of configuration design, expression method of configuration design, configuration design, and assembly parts structure configuration design.

The main configuration design work we practice have been: (1) with the line in seven different locations (only allowed to use seven) constitute the space sealing idle line frame ( lines can also be further restricted to equal); (2) space line design qualification; (3) with seven position plane (only seven) surrounded stereo; (4) according to a view paint a variety of other two views; (5) according to the two view draw third kinds of views; (6) develop to meet certain requirements (such as vertical, tangent, special intersecting etc.) (7) isometric transform; (8) form a combined revolving body; (9) with round and hexagonal plane composition pattern (includes several linear); (10) with the arc connection self pattern and dimension; (11) the structure of cup type stereo; (12) the design model of combination body; (13) the chimeras constructed by giving three-dimension; (14) according to the template design give the seamless model; (15) the representation model of design (at least four graphic expression); (16) structure with a screw, stud connection; (17) the configuration design of parts; (18) the assembly structure design.

\section{THE FUNCTION OF ENGINEERING GRAPHICS CONFIGURATION DESIGN}

As mentioned before, the configuration is the thinking process and presentation of the results obtained. Configuration activities fully reflect the various ways of thinking. Creative thinking and image thinking are particularly important and prominent. For example, in complete with seven positions, (seven) planes are surrounded by a three-dimensional configuration process. For the seven kinds of plane definition, projection property and materials on the legend are intuition thinking materials. A few hexagonal seven planes selected? How to combine? There can be many solutions to create divergent thinking and creative thinking. The above example shows that configuration activities can make students' training comprehensive, especially the creative thinking training. Graphics configuration is to draw class into creating activities and development thinking (especially creative thinking) garden.

The basic task of drawing course is training of spatial ability and spatial analysis ability. A manifestation of this ability is a combination of the peak section. It requires the use of projection analysis of the nature and form, analysis and judgment, transformation, synthesis of the known conditions, so the projection diagram is drawn out, and therefore the cultivation of spatial imagination is also a kind of thinking form[4]. The configuration of activities into the graphics course makes the students enter the creative activities of the world; the students will feel the broad field of vision.

The cultivation of configuration design and the training of thinking ability is the psychological process of people, which belongs to the intelligence aspect. But it must also be accompanied by active participation and support of non intelligence factors so as to promote each other, only in this way can the intelligence fully display the best state of thinking. The main non intelligence factors and configuration activities association are some subjective psychological factors, especially the psychological factors of young people (who seek to prevail over others, having strong sense of self-esteem, group consciousness and competition consciousness. When constructing an ordinary scheme, especially through the teachers' praise, he will feel great satisfaction. As a trainee said: I like to design their own homework, and I didn't like others. My own design work is praised, I feel proud, and I felt a real harvest. In the graphics configuration field, I will see the students in the best of spirits and active thinking. The configuration process is in highly excited state. In order to get the configuration satisfying, they even forget to eat and sleep. Because of the positive effect of non-intelligence factors, the configuration received excellent results: (1) In order to get the best configuration, the space thinking is strengthened; to make the configuration scheme perfect (2) Broaden the vision and ideas. Cultivate observation of the surrounding things, inspire innovation consciousness; (3) Speak from a certain meaning, operation is a kind of competition to make their works win, outstanding, pay attention to the aesthetic shape and drawing skills, and improve the level of operation; (4) The configuration process is always highly centralized to maximize the efficiency of thinking and improve teaching effect; (5) Due to the non intelligence factors occupying the dominant position, the negative things (such as fatigue, boredom, inertia and so on), improve the efficiency of the limited time in class teaching.

\section{SEVERAL PROBLEMS FOR GUIDING THE DESIGN}

In order to make the configuration design practice work around the teaching contents of Engineering Graphics smoothly, teachers must be timely in inspiration and guidance. Configuration design activities are like graphics sailing in the ocean, when students go toward a different route destination in the exploration, teachers should timely turn course to ensure reach the shore. In the configuration design, attention should be paid to the following aspects of guidance.

Configuration should be closely combined with the content and task of the course, and the relationship between the 
geometry and the projection base should be handled well. The design objective is to reinforce the latter, and it can not be separated from the latter one-sided pursuit of unconventional configuration. Students are often unable to control their thinking path and measure, such as some students only plan to use most of the time, resulting in the quality of drawing illegibility; some configuration is too complex, or beyond the teaching content, then resulting in inadequatity, it is difficult to complete. So each configuration problem must be with clear and specific requirements, scope, the workload and difficulty of limited content.

Configuration design must be based on the engineering feasibility. Engineering graphics configuration design is different from art configuration, and it should have its clear purpose and practicality. Configuration of engineering graphics design is a kind of training engineering talent; it will inevitably be restricted in engineering materials, structure type and process conditions. Engineering configuration is concrete, not abstract art. The artist can imagine and inspire to create fantastic works, satisfying people's spiritual enjoyment, but not the abstract works of art in many cases made of engineering products. For the students lack of engineering, materials, technology and other aspects of knowledge, teachers must timely give guidance.

The majority of students are interested in this creative activity characteristics, their enthusiasm is aroused, but often due to lack of certain theoretical knowledge and practice, or do not pay attention to the things around, or do not use the existing potential knowledge, do not know how to start. At this time the teacher's inspiration and guidance are particularly important. teachers should illustrate the configuration method and process, introduce the path of thinking, teaching students in accordance with their aptitude. The assembly configurations of the problem can be divided into: (1) give the structure principle; (2) gives a partial structure or give a view; (3) the schematic principle; (4) give the functional requirements; (5) completely by oneself. Obviously, from (1) to (5) the difficulty increases, so they can also be divided into mapping, improved type, and design type etc..

\section{REFERENCES}

[1] Tong Bingshu and Gao Shufeng. "Cultivate students innovation ability in teaching of engineering graphics. Journal of engineering graphics, 2008 (6): pp1-6.(in Chinese)

[2] Jiang Guirong and Zhao Bingli. "Research on the innovative thinking method in engineering graphics”. Teaching and research, 2005, vol28 (5): pp436-438. (in Chinese)

[3] Sun Wei, Chen Jinchang and Chen Liang. "Engineering drawing science exploration and practice in strengthening configuration creative design ability”. Journal of Donghua University. 2010, vol36 (4): pp457-461. (in Chinese)

[4] Wang Xiuying, Bai Haiying and Zhang Xiuzhi. "The cultivation of innovative talents of engineering graphics:The comprehensive practice” .Journal of engineering graphics, 2009 (5):pp149-152. (in Chinese) 